\title{
Urgences
}

\section{La quadrature du cercle, construction et pièges}

\section{Louise Beauchamp}

Numéro 29, octobre 1990

Éclats d'œuvre

URI : https://id.erudit.org/iderudit/025601ar

DOI : https://doi.org/10.7202/025601ar

Aller au sommaire du numéro

Éditeur(s)

Urgences

ISSN

0226-9554 (imprimé)

1927-3924 (numérique)

Découvrir la revue

Citer ce document

Beauchamp, L. (1990). La quadrature du cercle, construction et pièges.

Urgences, (29), 45-46. https://doi.org/10.7202/025601ar d'utilisation que vous pouvez consulter en ligne.

https://apropos.erudit.org/fr/usagers/politique-dutilisation/ 


\section{La quadrature du cercle, construction et pièges}

\section{Louise Beauchamp}

Étant donné que le langage a une fonction profondément négative qui n'est pas faite pour nommer quoi que ce soit de particulier mais l'absence de ce que l'on nomme.

Philippe Sollers

Au départ, il y a l'inconnaissance, cette voie d'humilité, celle qui comme un piège donne la liberté. Avoir cette (in)conscience que nous ne sommes qu'un lieu de passage ou un filtre. Pourtant, le doute persiste, un malaise profond, l'inquiétude.

Je fais des ronds sur le tapis

le temps d'évaluer quel coin

quel angle sera propice

me coucher en boule dessus

en faisant attention à ce que mes pieds

ne dépassent pas

c'est la quadrature du cercle

c'est un petit tapis

Il faut que je m'astreigne, car c'est mon travail d'écrire; que je dise la douleur des corps, la cassure des désirs qui restent latents, cette misère de vivre par procuration. L'écriture devrait me faire transgresser l'inavouable mais l'écriture m'amène dans la solitude. L'envie alors de copier sur quelqu'un, que les mots de cet * autre» me donnent le souffle qui me manque. Je me plais à rêver un long poème qui serait comme une intense prière ou une suite litanique, un poème au long souffle qui ne raconte pas d'histoire comme celle d'Ulysse dans L'odyssée, par exemple, bien que ce souffle soit un des plus beaux. Je peux dire ce que "cela" ne doit pas être, mais je suis incapable de définir le poème à venir. Il faut pourtant, je crois, avoir quelques certitudes, sans elles je deviens floue et le devient également ce que je regarde, ou ce que vous lisez ici. D'emblée, je préfêre me retrouver du côté du faire. 
46

diverses façons de présenter

disons si tu veux sans point ni

herse une fleur sous le balcon gris

pissenlit ou flocons brisés

Dans tout cercle, il y a un carré, et vice versa; question de point de vue. Bien entendu, certains carrés n'entrent pas dans certains cercles, même si l'on s'acharne, même si l'on déconstruit (ce n'est pas vrai non plus). En écrivant je cherche à bâtir une suite, une unité. A briser le cercle. Souventes fois les pièges sont de formes circulaires, pensons ici au collet simplement. Si l'on survit au piège, il y a la cage. Je sais.

Comment écrit-on? Pourquoi écrit-on? Se pose quelquefois pour moi la question de l'engagement de l'écrivain, ses responsabilités en tant que phare ou * surveillant".

Au mois d'avril dernier, à la radio, une nouvelle de l'Irak. On apprenait que l'État irakien faisait de nouveau la promotion du meurtre institutionnalisé. Cette justice permet le meurtre d'une femme, mais pire encore, l'encourage au nom d'une morale. Étant donné l'imagerie féerique entourant cette contrée, j'ai écrit alors dans mon journal * Bagdad n'est plus ce qu'elle était *.

Au départ

il y a l'abandon

notable

l'inévitable glissement

une glissade et une chute à la fois

l'artifice d'arrivée

les pieds brisés dans un collet

Imaginez ici une reproduction d'une peinture de Klee ou de Nicolas de Staël, à la rigueur de Mondrian, ou une histoire, toujours la même, celle de l'absence, où le dialogue ne se mesure pas en mots mais en silence. L'amour de l'un arrive quand notre amour pour lui finit, fatigué. C'est le chien qui se court après la queue, mais pour lui c'est un jeu. 